International Journal of Trend in Scientific Research and Development (IJTSRD)

Volume: 3 | Issue: 4 | May-Jun 2019 Available Online: www.ijtsrd.com e-ISSN: 2456 - 6470

\title{
A Study on Recent Trends in Recruitment Practices in India
}

\author{
S. Mukundhan
}

Faculty, Global College of Business Administration, Hubballi, Karnataka, India

\begin{abstract}
How to cite this paper: S. Mukundhan "A Study on Recent Trends in Recruitment Practices in India" Published in International Journal of Trend in Scientific Research and Development

(ijtsrd), ISSN: 2456-

6470, Volume-3 |

Issue-4, June 2019,

pp.749-751, URL:

https://www.ijtsrd.c

om/papers/ijtsrd23

902.pdf

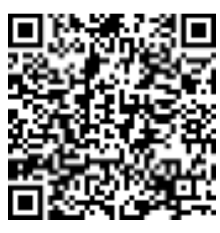

IITSRD23902
\end{abstract}

Copyright (C) 2019 by author(s) and International Journal of Trend in Scientific Research and Development Journal. This is an Open Access article distributed under the terms of the Creative Commons

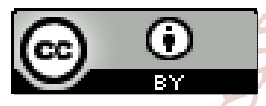
Attribution License (CC BY 4.0) (http://creativecommons.org/licenses/ by/4.0)

\section{ABSTRACT}

Gone were the days where the traditional method of recruitment would suffice to hire potential talents. But, since few decades the recruitment process has witnessed a sea of change due to the advent of the internet and its proliferation. Earlier the employer had the power during the job search, but in the recent trend, candidates have far more power during the job search. The potential candidates were considered to be the employee in the past, but the entire focus has changed and the candidates are being treated as customers. This dramatic change is all due to the changing phenomena of the internet and its vast coverage in the developing countries.

\section{Keywords: Recruitment, Internet, potential talents etc}

\section{INTRODUCTION}

Finding the right candidate for the job is the success mantra of recruitment. Whereas, the recruitment process involves analysing the requirements of a job, attracting employees, screening and selecting, and hiring. Traditionally, all the companies would opt for recruiting through the newspaper, employment exchange boards, employee referrals, online job portals etc. These methods were quite sufficient for hiring the right candidate. But in the current scenario with the advent of the internet, the recruiting practices have undergone major changes. Technology has not only helped to apply for jobs easier, but it has also made it easier for businesses to find qualified candidates anywhere in the world.
India accounts for more than $50 \%$ of its population below the age of 25 and more than $65 \%$ below the age of 35 , with an average age of 29 years. This population completely drools over the internet. The students who will be either graduating or postgraduates who are on the verge of finding jobs are not traditional employees. The recruitment agencies who find the candidates for the client companies will have a tough time finding these young I ndians elsewhere but online. The market is candidate driven and the ways of recruitment have completely changed. Traditional recruiters now should know if they want to hire an ideal candidate, it can also be through social networking sites, as these youngsters are active on the internet. In its elusive quest, social recruiting technology is easier than ever to succeed.

\section{Methodology}

The approach for this study is purely based on secondary research like the internet and articles on the same topic by various authors. The recruitment policy varies from organisations to organizations, that's the reason this study is considered for the organizations who have adopted the modern techniques of recruitment.

\section{Analysis}

There's a rapid change in the technology the world is witnessing right now, this, in turn, has impacted the way recruitment is taking place. numerous innovative practices are being used by recruiters these days such as;

\section{outsourcing}

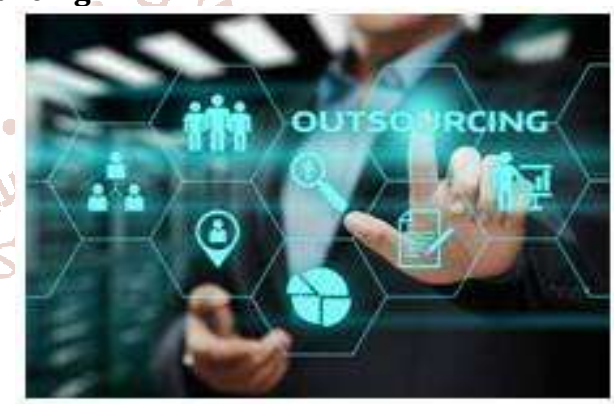

This method is usually undertaken by the companies as a cost-cutting measure and usually involves hiring a party outside a company to perform services that were previously performed by the company's own staff. By making an appropriate pool of ability the outsourcing firms help the association for screening the candidates for the necessities of the organization.

\section{E-Recruitment}

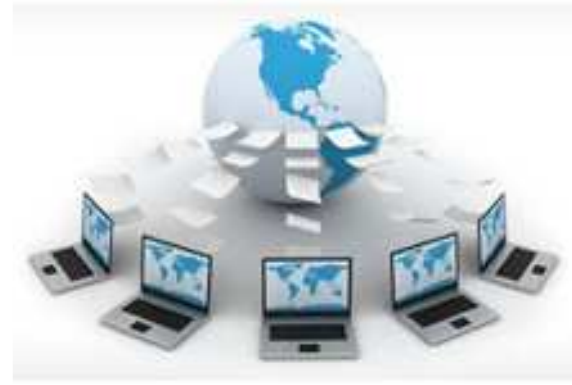


Internet is the main source of recruitment for many big organizations. the companies advertise their vacancies through their world wide web, the candidates, in turn, apply for these vacancies through company webpage. The major advantage this technique has is that it doesn't incur a high cost, and no intermediaries required and also there is a reduction of time for recruitment.

\section{Screening}

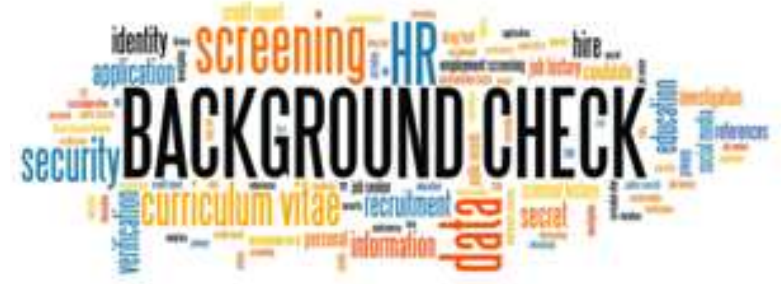

Due to artificial intelligence, the process of screening bulk amounts of candidates resumes has become easier. To ensure that no unsuitable candidates are screened, their job descriptions and resumes are matched by using artificial intelligence. This way it is quicker and more efficient to screen a candidate.

\section{Increased Demand for Employee Referrals}
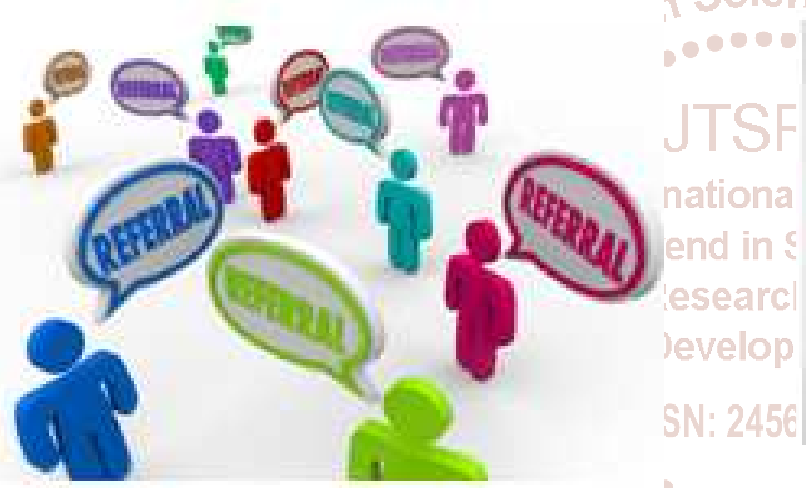

This is one of the most predictable trend recruitment is going to witness. Every organization relies upon employee referrals and in turn, the employee is paid bonuses on referrals.

Fig 1: Source Talentlyft

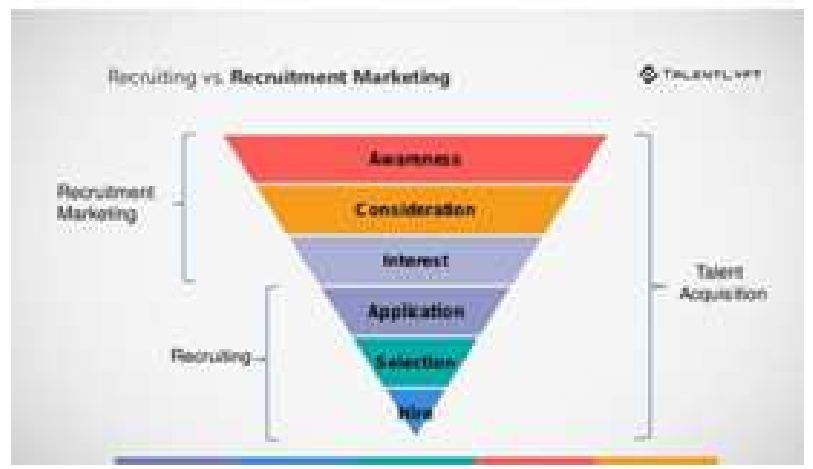

In traditional recruitment, there were no marketing phenomena being used. recently, recruitment marketing is the word evolved that includes putting marketing efforts to recruitment. Another such phenomenon that has been used is inbound marketing, where the company uses the strategy to proactively and continually attract candidates with the goal to make the candidates choose the company as the next employer.
Fig 2: Source LinkedIn

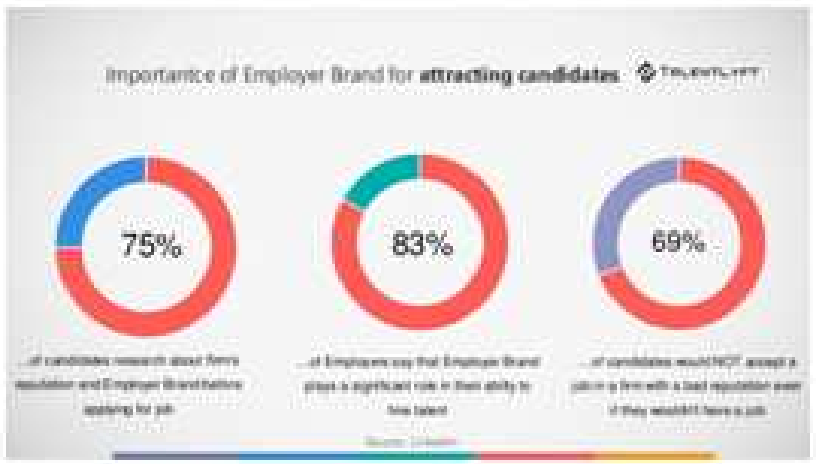

Employer brand is the trend picking up lately. As opposed to corporate brand reputation and value proposition employer brand has gained popularity.

"Candidate experience" is current, past and potential future candidates' overall perception of your company's recruiting process. It is based on candidates' feelings, behaviours and attitudes they experience during the whole recruiting process, from sourcing and screening to interviewing, hiring and finally onboarding.

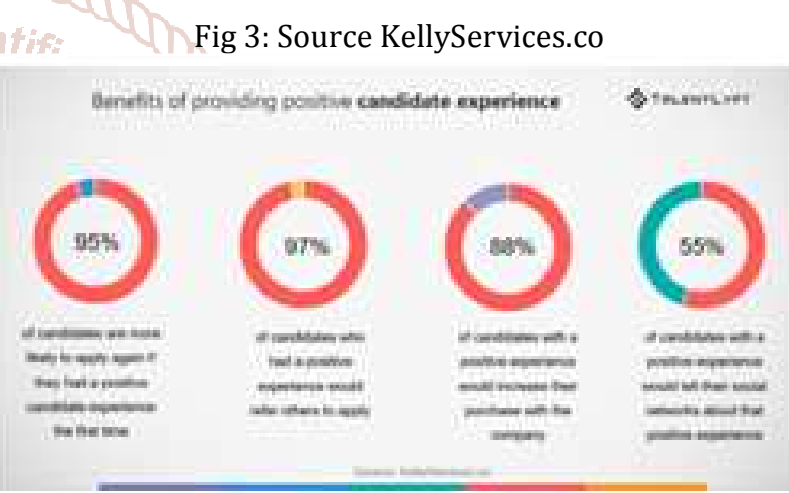

Candidates who had a positive response and experience in the recruitment process are more likely to accept a job offer, reapply in future and refer others to the company. But this also has an adverse impact, if the candidate experience is negative it can cost more than a few candidates to the company.

Fig 4: Source Infinity Social Media and Jobcast

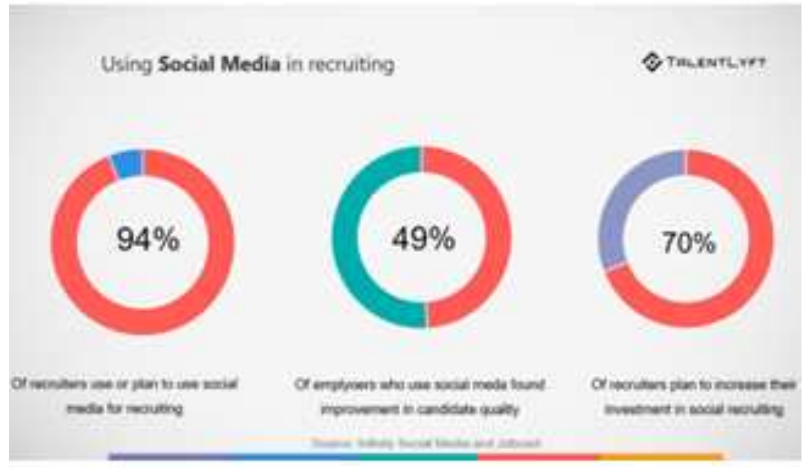

Apart from the above-mentioned practices, social recruiting too has influenced recruitment for instances like Facebook, Twitter, LinkedIn etc and also through websites like Glassdoor, blogs, forums, job boards. more than posting current vacant jobs ads on the company's social media network accounts goes beyond through social recruiting. 
Through social recruiting, the company can use social media networks in proactively searching the potential candidates and building a strong relationship with them.

Data-driven recruiting is also one of the aspects used to demonstrate recruiting methods through which HR planning and decision making are based on data acquired through HR technology such as Applicants Tracking system and Recruitment Marketing Platforms.

\section{Conclusion:}

In this rapidly changing technological world, the companies who adopt the innovations are the one that merely succeeds. It is not that the companies should completely avoid using traditional methods, they can be blended with the modern techniques of recruitment too. In order to catch up the pace with the youth population of India, it is indeed the need of the hour for all the recruiters to adapt the change in the recruitment practices.

\section{References:}

[1] https://theundercoverrecruiter.com/socialrecruiting-technology-changed-recruiting/

[2] https://www.cio.com/article/3180952/4-waystechnology-has-changed-recruitment-for-better-andworse.html

[3] https://www.hrhelpboard.com/recruitment/recenttrends-in-recruitment.html

[4] https://www.talentlyft.com/en/blog/article/87/15new-recruiting-trends-you-should-implement-in-2019updated

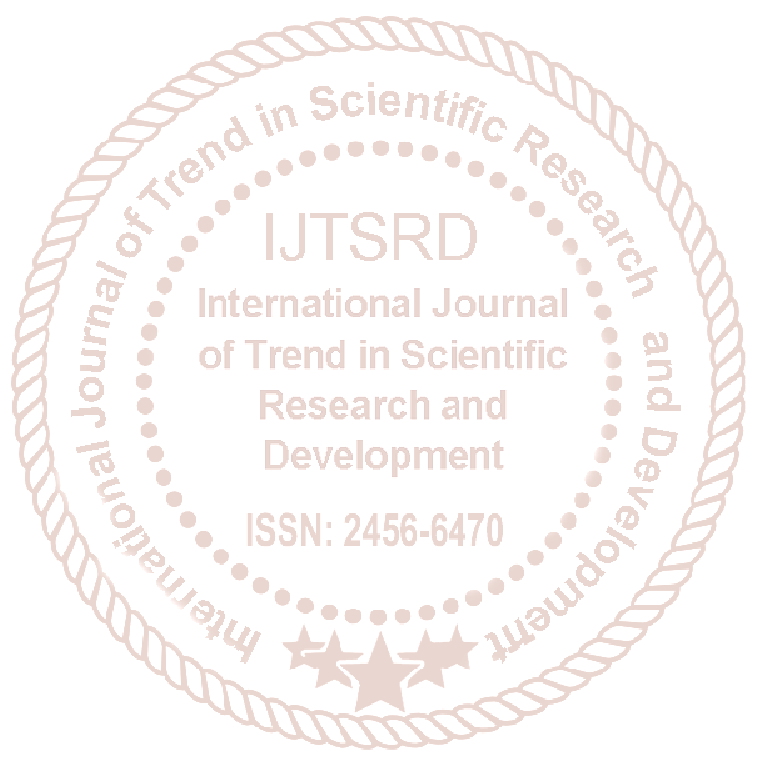

